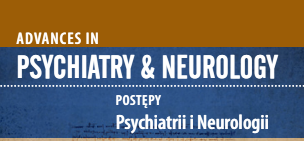

Correspondence to:

Halina Kadziela-Olech

Child and Adolescent Psychiatry Unit

University Children's Clinical Hospital

17 Waszyngtona Str.

15-274 Białystok, Poland

e-mail: halina.kadzielaolech@op.pl

Submitted: 05.07.2016

Accepted: 05.07.2017

\section{AFTER-EFFECTS OF HYPERKINETIC DISORDER (HKD) IN PROSPECTIVE LONGITUDINAL (12 YEARS) STUDY}

\author{
Halina Kądziela-Olech \\ Child and Adolescent Psychiatry Unit, University Children's Clinical Hospital, \\ Białystok, Poland
}

\begin{abstract}
Purpose: Despite the significant increase in the understanding of the hyperkinetic disorder (HKD), our knowledge of the factors associated with the persistence of the disorder and further development of psychopathology is insufficient. The long-term prospective studies have aimed at identifying factors that may determine the adverse course of HKD.

Methods: The study group 54 patients (95.1\% male) with HKD (mean age 8.1, SD \pm 1.7 years at the baseline assessment) was covered by a 12-year observation (mean age of participants: $19.1 \pm 1.7$ years at the end of the study). Subjects were comprehensively assessed with structured diagnostic interviews and assessments of cognitive functions, including the school and family functioning, the treatment as well as internalizing and externalizing problems.

Results: Statistical analysis of the severity of HKD indicated significant reduction in the symptoms after 12 years. The birth complications $(\mathrm{OR}=11.187 ; p=0.045)$, chronic conflicts in family $(\mathrm{OR}=0.129 ; p=0.018)$ and depression of mother $(\mathrm{OR}=6.033$; $p=0.045)$ have proved to be significant risk factors for externalizing disorders in the study group. The single-parent family $(\mathrm{OR}=0.099 ; p=0.009)$ and coexistence of mothers' anxiety disorders $(\mathrm{OR}=0.318 ; p=0.043)$ were a significant predictors for the model of internalizing disorders. Only $28(51.9 \%)$ of children used regular systematic therapy. Lack of the systematic treatment was a significant risk factor of transition of $\mathrm{HKD}$ to antisocial phenotypes (univariate regression model: $R=0.56 ; \mathrm{SE}=0.12 ; p<0.001$ ). Conclusions: Long-term clinical observation showed that the appropriate systematic treatment until adulthood may significantly reduce undesirable behaviours. Completion of the treatment programme should be monitored systematically for many years, which greatly influences the results of school education and increases the chances for correct psychosocial development. Parents' mental disorders/conflicts considerably decrease in the treatment effects, thereby increasing the risk of social maladjustment in patients with HKD.
\end{abstract}

Key words: hyperkinetic disorder, antisocial phenotype, development, risk factors, longitudinal observation.

\section{PURPOSE}

The phenotype including three domains, i.e. impulsivity, hyperactivity and inattention, is classified according to ICD-10 [1] as hyperkinetic disorder (HKD), which is referred to as a subset of attention deficit hyperactivity disorder (ADHD) by DSM-IV [2] and DSM-V [3]. Due to the rigorous criteria, prevalence of $\mathrm{HKD}$ is estimated to be approximately 1-2\% in school-age population [4]. Hyperkinetic disorder is a chronic neurodevelopmental disorder which hampers the child's developmental and adaptation processes and causes educational failures. Furthermore, it predisposes children to other psychopathological and social dysfunctions. Despite extensive research, the causative treatment continues to be unknown. Symptoms of inattention and impulsivity persist in adolescence and adult- hood in a significant proportion of patients $[5,6]$. They constitute a high risk of the occurrence of behavioural disturbances, delinquencies, psychoactive substances abuse, lack of education, unemployment, minor offences and traffic accidents [7-11].

So far, research has focused mainly on the course of attention-deficit hyperactivity disorder. The persisting repetitive patterns of antisocial behaviours meeting the criteria for conduct disorder in ICD-10 or DSM-IV/V are also the adverse consequence of ADHD [7, 9, 12, 13]. On the other hand, high incidence of affective disorders and anxiety disorders was found in adolescent and adult patients with ADHD diagnosed in childhood [14-17]. The phenotype of HKD in childhood seems important for both internalizing and externalizing disorders in adults. Internalizing disorders consist, according to 
the DSM-V Task Force (premature scientifically to propose alternative definitions for most disorders) of anxiety and depressed mood, however, the externalizing group is characterized by antisocial behaviours, conduct disturbances, addictions and impulse-control disorders [3].

Risk factors responsible for transition from HKD to so diverse disorders are still unclear. Therefore, the aim of this study was to evaluate the associations between HKD in childhood and psychopathology of young adults in prospective study. The author hypothesized that the longitudinal observation of the same group of children with homogeneous phenotype may allow to identify the determinants of adverse course of HKD.

\section{METHODS}

\section{Participants and procedure}

The research was carried out between 2002 and 2014. The study included 54 children with HKD symptoms (95.1\% male); mean age of this group at the moment the study was launched was 8.1 years $(\mathrm{SD} \pm 1.7)$. The consequences of hyperkinetic disorder were assessed more or less after 12 years of observation, when the care at the Psychiatric Outpatient Department was over (mean age of participants: 19.1 years; $S D \pm 1.7$ ). Research report prepared at this point of the study for each child included data on the family structure, parents' education, conflicts, mental illness and substance abuse in the family as well as pregnancy, gestational age at birth (weeks), birth complications, weight at birth, Apgar score, coherence and consistency in the child care. The diagnosis of HDK, which was performed according to the criteria of ICD-10 [1], requires the symptoms of three domains (at least 6 of 9 items of inattention; at least 3 of 5 items of hyperactive and at least 1 of 4 of impulsivity). Severity of the disorder was measured by using the Polish version (authorized translation) of NICHQ Vanderbilt Assessment Scale for Parent (VADPRS) and for Teacher (VADTRS) [18]. In the study group, these symptoms were shown before the child reached 6 years of age. The symptoms were manifested in many situations and they continued on regular basis for more than 6 months, significantly impairing the child's school and social functioning. Exclusion criteria of the study group were other psychiatric or neurodevelopmental disorders, epilepsy, mental retardation, brain injury, such as head trauma with loss of consciousness, or chronic somatic diseases. All participants in the study were administered the Wechsler Intelligence Scale for Children - Revised (WISC-R, Polish adaptation) [19]. Each child with HKD underwent an individual therapy at an outpatient department. During periodic visits (every month), the following methods were applied: psychoeducation and training of parents, behavioural-cognitive training with a reward system for children and educational procedures addressed to teachers. Medication treatment was used only in aggravation of symptoms, because there are no strict recommendations on the choice of drugs for hyperkinetic disorder. Assuming that the structure and coherence are the most optimal factors in the case of $\mathrm{HKD}$, the parents' consistency with the course of the treatment was evaluated. Patients were assessed for current HKD status and psychiatric disorder (externalizing and internalizing) at the follow-up assessment.

\section{Statistical analysis}

All statistical analyses were performed using the Statistica 10.0 PL (StatSoft), PASW Statistics 17.0 (Predictive Solutions) and Statu 12.1. The relationship between qualitative features was checked by the $\chi^{2}$ test of independence and the Fisher's exact test. Since many variables were not normally distributed according to the Kołmogorow-Smirnow test with Lillefors' correction and the Shapiro-Wilk test, the analysis used non-parametric tests: the Kruskal-Wallis test with post-hoc test and the Wilcoxon signed rank test and Spearman's rank correlation. The values of the variables are presented as mean \pm SD or median, first and third quartile. The regression analysis was performed. The univariate and multivariate linear regression models were created. The $p$-value at the level of 0.05 was considered statistically significant.

The study was approved by the Ethics Committee of the Medical University of Bialystok, in accordance with the principles of the Guidelines for Good Clinical Practice.

\section{RESULTS}

Statistical analysis of the distribution of values obtained in ICD-10, where median (middle value) in the examined in preliminary study amounted to 15 scores (at dispersion from 10 to 18 ) and after 12 years - 8 scores (at dispersion from 5 to 11), indicated significant differences in decreasing in the characteristic symptoms for HKD in childhood $(Z=5.58, p<0.001)$ (Figure I).

At the moment of completing the psychiatric outpatient care, in 19.1-year-old patients a high percentage of externalizing disorders (conduct disorders, nicotine use) (37\%) along with internalizing disorders (anxiety and depressive symptoms) (35.2\%) was found. The comparative analysis of the study groups is presented in Table 1 . The duration of breastfeeding of children with HKD (mean $=5.3$; SD 6.0 months) in the internalizing group (mean $=5.8$; SD 6.8) was significantly longer as compared with the externalizing group (mean $=3.6$; SD 5.3 months). Singleparent families $(47.4 \%)$ were more frequent in patients with internalizing disorders. Parents of the study group with externalizing disorders were less educated $(30.0 \%$ 


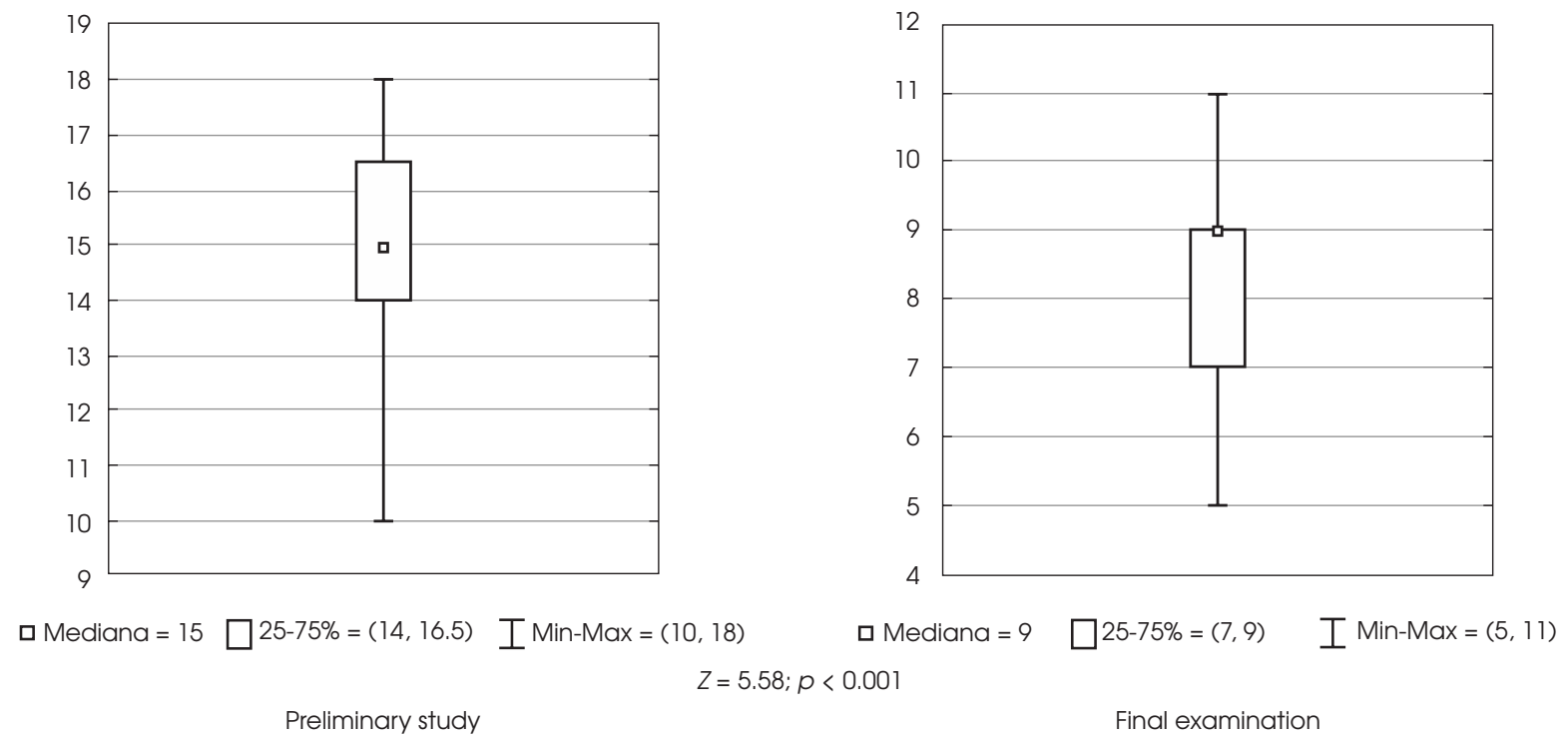

Figure 1. Distribution of symptoms of hyperkinetic disorder at both time points

mothers and $35.0 \%$ fathers with elementary education). In this group, $85.0 \%$ ( $p=0.002)$ of carers exhibited inconsistency in dealing with the child. In the examined group, the mental disorders were more frequent in the families which did not use recommendations imparted during treatment $(70.0 \%$ parents), and fathers abused alcohol significantly more frequently (40.9\%).

A logistic regression model was constructed to identify the predictors of anxiety (internalizing) and conduct disorders (externalizing) in the examination groups. The single-parent families coexisting with the mothers' anxiety disorders were a significant predictor for the model of internalizing disorders (Table 2).

Birth complications, chronic conflicts in family and depression of mother have proved to be significant risk factors for externalizing disorders in the study group (Table 3). Of the group of 54 patients with HKD only $28(51.9 \%)$ of children used regular systematic therapy (visits every month) throughout the observation period, whereas in $26(48.1 \%)$ cases the visits were sporadic, once or twice a year, usually because of upbringing or educational problems. Lack of the systematic treatment was a significant risk factor of transition of HKD to externalizing disorders; univariate regression model: $R=0.56$; $\mathrm{SE}=0.12 ; p<0.001$.

\section{DISCUSSION}

Certain limitation of this study was the small group size. However, the author's intention was to include children with a very similar phenotype of HKD. Despite increased awareness that attention deficit hyperactivity disorder continues into adulthood, the research of transition symptoms of HKD to other psychopathology in ontogeny is open. The symptoms of HKD, as the studies indicate, do not subside [20,21], but can be 'hidden' in another psychopathology of adulthood. Signs of core domains in the attention deficit and impulsivity are present in varying degree in the psychopathology of adults $[15,22]$. In the study group, the percentage of 19-year-old people with externalizing disorders complying with the $\mathrm{CD}$ criteria according to ICD-10 was $37 \%$. It should be noted that the internalizing disorders had been in a similar proportion (35.2\%) on completion of this research. Many years of observation of the same group of patients showed that HKD is a chronic disease and lack of systematic long-term treatment increases the risk of HKD transition to antisocial phenotypes.

Although HKD is a genetically conditioned neurodevelopmental disorder of inattention and impulse control $[23,24]$, the environmental factors may play an important part in the behavioural phenotype [25-29]; they may also contribute to further development of psychopathology. Undoubtedly, the environmental factors responsible for gene expression regulation largely contribute to the pathological symptoms but the mechanism of mutual interaction in the long-term is not fully understood. The author found a significant relationship between the single-parent family coexistence of mothers' anxiety disorders and internalizing disorders of the participants. The combination of events, such as birth complications, mother's depression and chronic conflict in the family, was significantly related to the occurrence of antisocial symptoms in the study group of children with HKD. Further, in the examined group, the duration of breastfeeding was shorter in patients with externalizing disorders. While the role of the breastfeeding in the brain develop- 
Table 1. Comparative analysis of the study groups

\begin{tabular}{|c|c|c|c|c|}
\hline Data & ID $(n=19)$ & $\mathrm{ED}(n=20)$ & $\begin{array}{l}\text { HKD without ID/ED } \\
\qquad(n=15)\end{array}$ & $p$ \\
\hline Gestational age at birth (week) & 37.6 (SD 2.197) & 37.9 (SD 1.69) & 37.8 (SD 3.18) & \\
\hline Pathology of pregnancy & $10.5 \%$ & $14.3 \%$ & $26.7 \%$ & \\
\hline Birth complications & $15.8 \%$ & $21.4 \%$ & $6.7 \%$ & \\
\hline Weight at birth (g) & $3144.2 \pm 611.4$ & $3092.8 \pm 461.4$ & $3133.5 \pm 710.8$ & \\
\hline Apgar score & 8.5 (SD 2.7) & $9.2(\mathrm{SD} 1.3)$ & $9.3(\mathrm{SD} 1.3)$ & \\
\hline Duration of breastfeeding (month) & $5.8(S D$ 6.8)* & $3.6(\mathrm{SD} 5.3)^{*}$ & $4.1(\mathrm{SD} 2.6)^{*}$ & 0.005 \\
\hline Total IQ & 94.1 (SD 14.4) & $100.3(S D 11.9)$ & 99.4 (SD 9.2) & \\
\hline Repetition of class & $10.5 \%$ & $55.0 \%$ & $28.6 \%$ & \\
\hline Systematic therapy & $47.4 \%$ & $15.0 \%$ & $78.6 \%$ & \\
\hline \multicolumn{5}{|l|}{ Family } \\
\hline With both parents & $52.6 \%$ & $65.0 \%$ & $78.6 \%$ & \\
\hline Single parent & $47.4 \%$ & $35.0 \%$ & $21.4 \%$ & \\
\hline Disclosed chronic conflicts & $21.1 \%{ }^{* a}$ & $85.0 \% * a$ & $33.3 \%{ }^{* a}$ & 0.04 \\
\hline Inconsistency & $52.6 \%$ & $85.0 \% * a$ & $20.0 \% * a$ & 0.002 \\
\hline \multicolumn{5}{|l|}{ Mother's education } \\
\hline Higher & $10.5 \%$ & $20.0 \%$ & $21.4 \%$ & \\
\hline Secondary & $47.4 \%$ & $15.0 \%$ & $42.9 \%$ & \\
\hline Vocational & $26.3 \%$ & $35.0 \%$ & $14.3 \%$ & \\
\hline Elementary & $15.8 \%$ & $30.0 \%$ & $21.4 \%$ & \\
\hline \multicolumn{5}{|l|}{ Father's education } \\
\hline Higher & $5.3 \%$ & $15.0 \%$ & $21.4 \%$ & \\
\hline Secondary & $31.6 \%$ & $10.0 \%$ & $28.6 \%$ & \\
\hline Vocational & $26.3 \%$ & $40.0 \%$ & $28.6 \%$ & \\
\hline Elementary & $15.8 \%$ & $35.0 \%$ & $21.4 \%$ & \\
\hline \multicolumn{5}{|l|}{ Mother's mental disorders } \\
\hline Depression & $5.3 \%$ & $20.0 \%$ & - & \\
\hline Anxiety disorders & $21.1 \%$ & $5.0 \%$ & - & \\
\hline Nicotine dependence & $10.5 \%$ & $35.0 \%$ & $14.3 \%$ & \\
\hline Alcoholism & $5.3 \%$ & $15.0 \%$ & - & \\
\hline Schizophrenia & - & - & $7.1 \%$ & \\
\hline \multicolumn{5}{|l|}{ Father's mental disorders } \\
\hline Depression & $5.3 \%$ & $10.0 \%$ & $7.1 \%$ & \\
\hline Nicotine dependence & $5.3 \%$ & $35.0 \%$ & $7.1 \%$ & \\
\hline Alcoholism & $15.8 \%$ & $65.0 \%$ & $28.6 \%$ & \\
\hline
\end{tabular}

ID - internalizing disorders, ED - externalizing disorders, HKD without ID/ED - hyperkinetic disorder without internalizing disorders and internalizing disorders *Significant difference between groups $p$ (Mann-Whitney U-test) $<0.05$

*aSignificant difference between groups $p\left(x^{2}\right)<0.05$

Table 2. The predictors of internalizing disorders in study group with hyperkinetic disorder

\begin{tabular}{|l|c|c|c|}
\hline Internalizing disorders & OR & p-value* & 95\% Cl \\
\hline Single-parent & 0.099 & 0.009 & $0.0176-0.562$ \\
\hline Maternal anxiety disorders & 0.318 & 0.043 & $0.0334-0.999$ \\
\hline
\end{tabular}

*Statistically significant predictors in logistic regression model 
After-effects of hyperkinetic disorder (HKD) in prospective longitudinal (12 years) study

Table 3. The predictors of externalizing disorders in study group with hyperkinetic disorder

\begin{tabular}{|l|c|c|c|}
\hline Externalizing disorders & OR & p-value* & $\mathbf{9 5 \%} \mathrm{Cl}$ \\
\hline Birth complications & 11.187 & 0.045 & $1.060-118.004$ \\
\hline Chronic conflicts & 0.129 & 0.018 & $0.024-0.706$ \\
\hline Mother's depression & 6.033 & 0.045 & $1.044-34.843$ \\
\hline
\end{tabular}

${ }^{*}$ Statistically significant predictors in logistic regression model

ment still remains unclear, it is possible that the some cognitive or behavioural dysfunction may be the result of the short duration of breastfeeding [30]. Other longitudinal studies have confirmed that interactions between biological vulnerability and poor parenting are important in predicting further externalising problems [5, 31-33]. Children with HKD may be at risk of becoming a group of emotional deprivation, particularly if parents experience mental disorders $[31,33]$. Parents present the relations with their children as stressful and giving no satisfaction. Child's disorganized activities usually evoke negative reactions of caregivers. Long-lasting lack of positive responses from the family may reinforce the child's dysfunctional behaviours and problems with social adjustment. Research finds that family functioning may be an important determinant of course of HKD. When behavioural or psychological difficulties appear, parents need to understand this problem, the meaning of specific symptoms and their causes as well as the treatment effects and consequences. The therapeutic interventions comprise also of supporting carers' skills and teaching them the strategies of taking care of a child, which change as the child development.

\section{CONCLUSIONS}

1. Long-term clinical observation showed that the HKD is a chronic disease, and appropriate systematic treatment until adulthood may significantly reduce undesirable behaviours.

2. Completion of the treatment programs should be monitored systematically for many years, which greatly influences the results of school education and increases the chances for correct psychosocial development.

3. Parents' mental disorders/conflicts considerably reduce the treatment effects, thereby.

\title{
Acknowledgements
}

\begin{abstract}
Author is grateful to the certified psychologist Anna Klimek for psychological diagnosis of children and is grateful to bio-statistician Dr Robert Milewski from Department of Statistics and Medical Informatics of Medical University of Bialystok for help in the statistical analysis. Author would also like to thank Jason Crase Editorial Specialist of the Division of Publishing and Production Services in the American Academy of Pediatrics (AAP) and Pat Heinrich Chief Quality Improvement Director of The National Initiative for Children's Healthcare Quality (NICHQ) for the availability of NICHQ Vanderbilt Assessment Scales.
\end{abstract}

\section{Conflict of interest}

Absent.

Financial support

Absent.

\section{References}

1. The ICD-10 Classification of Mental and Behavioral Disorders: Clinical Descriptions and Diagnostic Guidelines. Geneva: World Health Organization; 1992.

2. Diagnostics and Statistical Manual of Mental Disorders, Fourth Edition, Text Revision DSM-IV-TR. Washington: American Psychiatric Association; 2000.

3. Diagnostics and Statistical Manual of Mental Disorders, Fifth Edition, DSM - V. Washington, London: England American Psychiatric Association; 2013.

4. Swanson JM, Sergeant JA, Taylor E, Sonuga-Barke EJ, Jensen PS, Cantwell DP. Attention - deficit hyperactivity disorder and hyperkinetic disorder. Lancet 1998; 351: 429-433. 
5. Biederman J, Petty CR, Clarke A, Lomedico A, Faraone SV. Predictors of persistent ADHD: an 11-year follow-up study. J Psychiatr Res 2011; 45: 150-155.

6. Klein RG, Mannuzza S, Olazagasti MA, Roizen E, Hutchison JA, Lashua EC, et al. Clinical and functional outcome of childhood attention-deficit/hyperactivity disorder 33 years later. Arch Gen Psychiatry 2012; 69: 1295-1303.

7. Barkley RA, Fischer M, Smallish L, Fletcher K. Young adult follow-up of hyperactive children: antisocial activities and drug use. J Child Psychol Psychiatry 2004; 45: 195-211.

8. Dalsgaard S, Mortensen PB, Frydenberg M, Thomsen PH. Long-term criminal outcome of children with attention deficit hyperactivity disorder. Crim Behav Ment Health 2013; 23: 86-98.

9. Garg J, Arun P. A Follow-up Study of Academic Functioning and Social Adjustment in Children with Attention Deficit Hyperactivity Disorder. Indian J Psychol Med 2013; 35: 47-52.

10. Van den Ban, Souverein P, Meijer W, van Engeland H, Swaab H, Egberts T, et al. Association between ADHD drug use and injuries among children and adolescents. Eur Child Adolesc Psychiatry 2014; 23: 95-102.

11. Wehmeier PM, Schacht A, Barkley RA. Social and emotional impairment in children and adolescents with ADHD and the impact on quality of life. J Adolesc Health 2010; 46: 209-217.

12. Mandy W, Skuse D, Steer C, St Pourcain B, Oliver BR. Oppositionality and socioemotional competence: interacting risk factors in the development of childhood conduct disorder symptoms.J Am Acad Child Adolesc Psychiatry 2013; 52: 718-727.

13. Taurines R, Schmitt J, Renner T, Conner AC, Warnke A, Romanos M. Developmental comorbidity in attention-deficit/hyperactivity disorder. Atten Defic Hyperact Disord 2010; 2: 267-289.

14. Bilgic A, Türkoğlu S, Ozcan O, Tufan AE, Yilmaz S, Yuksel TY. Relationship between anxiety, anxiety sensitivity and conduct disorder symptoms in children and adolescents with attention-deficit/hyperactivity disorder (ADHD). Eur Child Adolesc Psychiatry 2013; 22: 523-532.

15. Chao CY, Gau SS, Mao WC, Shyu JF, Chen YC, Yeh CB. Relationship of attention-deficit-hyperactivity disorder symptoms, depressive/anxiety symptoms, and life quality in young men. Psychiatry Clin Neurosci 2008; 62: 421-426.

16. Humphreys KL, Katz SJ, Lee SS, Hammen C, Brennan PA, Najman JM. The association of ADHD and depression: mediation by peer problems and parent-child difficulties in two complementary samples. J Abnorm Psychol 2013; 122: 854-867.

17. Yoshimasu K, Barbaresi WJ, Colligan RC, Voigt RG, Killian JM, Weaver AL, et al. Childhood ADHD is strongly associated with a broad range of psychiatric disorders during adolescence: a population-based birth cohort study. J Child Psychol Psychiatry 2012; 53: 1036-1043.

18. Vanderbilt Assessment Scales (Parent - informant, Teacher - informant). In: Caring for Children With ADHD: A Resource Toolkit for Clinicians. National Initiative for Children's Healthcare Quality NICHQ and American Academy of Pediatrics; 2002.

19. Wechsler D. WISC-R Manual for the Wechsler Intelligence Scale for Children-Revised. New York: Psychological Corporation; 1974.

20. Swift KD, Sayal K, Hollis C. ADHD and transitions to adult mental health services: a scoping review. Child Care Health Dev 2014; 40: 775-786.

21. Van Cleave J, Leslie LK. Approaching ADHD as a chronic condition: implications for long-term adherence. J Psychosoc Nurs Ment Health Serv 2008; 46: 28-37.

22. Fones CS, Pollack MH, Susswein L, Otto M. History of childhood attention deficit hyperactivity disorder (ADHD) features among adults with panic disorder. J Affect Disord 2000; 58: 99-106.

23. Barkley RA. Behavioral inhibition, sustained attention, end executive functions: Constructing a unifying theory of ADHD. Psychol Bull 1997; 121: 65-94.

24. Gupta R, Kar BR. Development of attentional processes in ADHD and normal children. Prog Brain Res 2009; 176: 259-276.

25. Boksa P, El-Khodor BF. Birth insult interacts with stress at adulthood to alter dopaminergic function in animal models: possible implications for schizophrenia and other disorders. Neurosci Biobehav Rev 2003; 27: 91-101.

26. Larsson J, Larsson H, Lichtenstein P. Genetic and environmental contributions to stability and change of ADHD symptoms between 8 and 13 years of age: A longitudinal twin study. J Am Acad Child Adolesc Psychiatry 2004; 43: 1267-1275.

27. Lenroot RK, Gledd JN. The changing impact of genes and environment on brain development during childhood and adolescence: initial findings from a neuroimaging study of pediatric twins. Dev Psychopathol 2008; 20: 1161-1175.

28. Nigg J, Nikolas M, Burt SA. Measured gene-by-environment interaction in relation to attention-deficit/hyperactivity disorder. J Am Acad Child Adolesc Psychiatry 2010; 49: 863-873.

29. Bornovalova MA, Cummings JR, Hunt E, Blazei R, Malone S, Iacono WG. Understanding the relative contributions of direct environmental effects and passive genotype-environment correlations in the association between familial risk factors and child disruptive behavior disorders. Psychol Med 2014; 44: 831-844.

30. Deoni SC, Dean DC III, Piryatinsky I, O’Muircheartaigh J, Waskiewicz N, Lehman K, et al. Breastfeeding and early white matter development: A cross-sectional study. Neuroimage 2013; 82: 77-86.

31. Raine A, Brennan P, Mednick SA. Birth complications combined with early maternal rejection at age 1 year predispose to violent crime at age 18 years. Arch Gen Psychiatry 1994; 51: 984-988.

32. Shaw DS, Winslow EB, Owens EB, Vondra JI, Cohn JF, Bell RQ. The development of early externalizing problems among children from low-income families: A transformational perspective. J Abnorm Child Psychol 1998; 26: 95-107.

33. Morrell J, Murray L. Parenting and the development of conduct disorder and hyperactive symptoms in childhood: a prospective longitudinal study from 2 months to 8 years. J Child Psychol Psychiatry 2003; 44: 489-508. 